Original Research

\title{
Photocatalytic Degradation of Azo Dyes Using Microreactors: Mechanistic Study of its Effects on $\mathrm{H}_{2} \mathrm{O}_{2}$ Addition
}

Minato Nakamura, Yoshinori Murakami *

National Institute of Technology, Nagaoka College, Nagaoka, Niigata 940-8532, Japan; E-Mails: murakami mb@nagaoka-ct.ac.jp; $\underline{\text { m nakamura@seed.co.jp }}$

* Correspondence: Yoshinori Murakami; E-Mail: murakami_mb@nagaoka-ct.ac.jp

Academic Editor: Ewa Kowalska

Special Issue: $\underline{\text { Advances in Photocatalysis }}$

Catalysis Research

2021, volume 1 , issue 3

doi:10.21926/cr.2103002
Received: August 17, 2021

Accepted: September 03, 2021

Published: September 13, 2021

\begin{abstract}
The photocatalytic reaction involved in $\mathrm{TiO}_{2}$ photocatalysis was investigated using a microreactor coated with $\mathrm{TiO}_{2}$ film on the glass plate attached on one side of the microreactor. It was confirmed that the effect of $\mathrm{H}_{2} \mathrm{O}_{2}$ on the photocatalytic degradation efficiency of azo dyes (acid orange 7, acid red 151, and acid yellow 23) was dependent on the polymorphs (anatase and rutile) of $\mathrm{TiO}_{2}$ coated on the glass plate of the UV-irradiated microreactor. Scavengers of holes (KI) and electrons ( $p$-benzoquinone) were added to the solution of azo dyes, and their effects on the degradation efficiencies of the azo dye (acid orange 7) in the microreactor system were investigated. It was found that the electron scavengers of p-benzoquinone showed much larger effects on the photocatalytic degradation efficiency than the hole scavengers of $\mathrm{KI}$. Based on these results, the mechanism of the photocatalytic degradation of the azo dyes in the presence of $\mathrm{H}_{2} \mathrm{O}_{2}$ was proposed.
\end{abstract}

\section{Keywords}

Photocatalysis; $\mathrm{TiO}_{2}$; microreactor; azo dye; degradation; $\mathrm{H}_{2} \mathrm{O}_{2}$; anatase; rutile

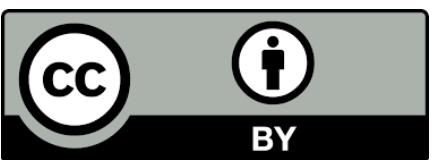

(C) 2021 by the author. This is an open access article distributed under the conditions of the Creative Commons by Attribution License, which permits unrestricted use, distribution, and reproduction in any medium or format, provided the original work is correctly cited. 


\section{Introduction}

Photocatalysis is known to degrade organic compounds, inactivate or remove viruses, and finds a wide range of applications [1-4]. Among them, $\mathrm{TiO}_{2}$ is a widely used photocatalyst due to its low cost, non-toxicity, and good oxidizing nature $[5,6]$. $\mathrm{TiO}_{2}$ exists as three polymorphs of anatase (tetragonal), rutile (tetragonal), and brookite (orthorhombic) [7]. Since it is difficult to prepare the brookite $\mathrm{TiO}_{2}$ without anatase and rutile phases [8], the photocatalytic activities and stabilities are mainly investigated for anatase and rutile $\mathrm{TiO}_{2}$. Although rutile $\mathrm{TiO}_{2}$ is the stable form and anatase is the metastable form, the latter has higher photocatalytic activity than the former type [9]. Recently, Zhang et al. [10] investigated the difference in the photocatalytic activities of the three polymorphs using density functional theory calculations and suggested that the differences were attributed to the longer lifetime of the photoexcited electrons and holes in anatase due to its indirect transition, while rutile and brookite showed direct transition. Also, the effective mass of photogenerated electrons in anatase was lowest, which eased the migration of the photoexcited electrons compared to those in rutile and brookite forms.

The effects of $\mathrm{H}_{2} \mathrm{O}_{2}$ addition on the photocatalytic activities of $\mathrm{TiO}_{2}$ have been extensively investigated $[11,12]$ to study the enhancement in the degradation rate of organic compounds. The accelerated degradation rate of the organic compounds was attributed to the oxidation of $\mathrm{OH}$ radicals formed by the UV-light photolysis of $\mathrm{H}_{2} \mathrm{O}_{2}$ and the photocatalytic reaction of $\mathrm{H}_{2} \mathrm{O}_{2}$ with photogenerated electrons on the $\mathrm{TiO}_{2}$ surfaces (i.e., $\mathrm{H}_{2} \mathrm{O}_{2}+\mathrm{e}^{-} \rightarrow \mathrm{OH}+\mathrm{OH}^{-}$) in addition to the heterogeneous photocatalytic redox reactions on the surface. Li et al. [13] observed the photodecomposition of $\mathrm{H}_{2} \mathrm{O}_{2}$ on the $\mathrm{TiO}_{2}$ surface under visible light irradiation and detected $\mathrm{OH}$ radicals by the ESR spectroscopic technique. Based on these results, the reaction mechanism for the decomposition of $\mathrm{H}_{2} \mathrm{O}_{2}$ on the $\mathrm{TiO}_{2}$ surface by the photocatalytic reduction reaction, such as $\mathrm{H}_{2} \mathrm{O}_{2}$ on $\mathrm{TiO}_{2}+\mathrm{e}^{-} \rightarrow \mathrm{OH}+\mathrm{OH}^{-}$, was elucidated. Furthermore, Li et al. [13] investigated the mechanism of $\mathrm{H}_{2} \mathrm{O}_{2}$ decomposition by monitoring the $\mathrm{HO}_{2}$ radical diffused from the $\mathrm{TiO}_{2}$ surfaces in the gas phase using the cavity ring-down method. The $\mathrm{HO}_{2}$ radicals diffused from the $\mathrm{TiO}_{2}$ surfaces were successfully detected in the gas phase. Also, it was found that the lifetime of the $\mathrm{HO}_{2}$ radicals was dependent on the type of $\mathrm{TiO}_{2}$. Thus, it was concluded that the $\mathrm{HO}_{2}$ radicals were generated by the photocatalytic reaction on the $\mathrm{TiO}_{2}$ surface, not by the photolysis of $\mathrm{H}_{2} \mathrm{O}_{2}$ in the gas phase.

The direct detection of $\mathrm{OH}$ radicals released by the photocatalytic reaction on $\mathrm{TiO}_{2}$ was performed by Nosaka and co-workers using coumarin and terephthalate as the fluorescence probe of the radicals $[14,15]$. The effect of $\mathrm{H}_{2} \mathrm{O}_{2}$ addition on the amount of $\mathrm{OH}$ radicals formed by the photocatalytic reaction was studied. The amount of $\mathrm{OH}$ radicals increased in rutile $\mathrm{TiO}_{2}$ but decreased in the anatase form. Thus, the difference in the reactivity of $\mathrm{H}_{2} \mathrm{O}_{2}$ for anatase and rutile surfaces caused the difference in the effect of $\mathrm{H}_{2} \mathrm{O}_{2}$ addition on the amount of $\mathrm{OH}$ radicals generated by the photocatalytic reaction. Since the photocatalytic activity was dependent not only on the polymorphs of $\mathrm{TiO}_{2}$ but also on other parameters such as particle diameter, the comparison of the photocatalytic activity of the three $\mathrm{TiO}_{2}$ polymorphs in the film form was preferable. 
Recently, microreactors have attracted much attention as the reactions can be regulated in more precise and controlled conditions than those in a batch reactor [16]. There were numerous studies on photocatalytic reactions using microreactors. The review articles on the photocatalytic reaction using microreactors are also available in the literature 17 [17]. In the present study, the effect of $\mathrm{H}_{2} \mathrm{O}_{2}$ addition on the $\mathrm{TiO}_{2}$ photocatalytic reactions using conventional microreactor systems was investigated, and the difference in the reactivity of $\mathrm{H}_{2} \mathrm{O}_{2}$ for anatase and rutile surfaces was determined by measuring the degradation of azo dyes inside the microreactors. Since the photocatalytic microreactor system avoids the complexity arising from the particle dispersion or aggregation in the $\mathrm{TiO}_{2}$ suspension during the photocatalytic reaction, it is a desirable reactor to investigate such polymorph dependency of the $\mathrm{H}_{2} \mathrm{O}_{2}$ addition on the $\mathrm{TiO}_{2}$ photocatalytic reaction.

\section{Experimental Methods}

\subsection{Fabrication of the $\mathrm{TiO}_{2}$ Film on a Microreactor}

The microreactor purchased from Key Chem-Lumi Co. Ltd. was used for the study without any further modification. It has an internal channel width of $1.0 \mathrm{~mm}$, depth of $0.5 \mathrm{~mm}$, and length of $1100 \mathrm{~mm}$. In order to avoid the disclosure of the channel of the microreactor, $\mathrm{TiO}_{2}$ film was deposited on the inner side of the quartz window in the microreactor by the sol-gel calcination method, as shown in Figure 1(a). The calcination temperature for the $\mathrm{TiO}_{2}$ sol on the glass substrate was set to $200{ }^{\circ} \mathrm{C}$. The $\mathrm{TiO}_{2}$ sols of the anatase form (AT-01) were purchased from Photo-Catalytic Materials Co. Ltd., and those of the rutile form (RA-06) were a generous gift from Taki Chemical Co. Ltd. The crystal structure of $\mathrm{TiO}_{2}$ on the glass substrate was verified by measuring the XRD patterns of each $\mathrm{TiO}_{2}$ film, as shown in Figure 2.

(a)

$\square$ Microreactor

\begin{tabular}{|c|}
\hline Quartz glass \\
\hline channel \\
microreactor \\
\hline
\end{tabular}

\section{Microreactor photocatalyst}

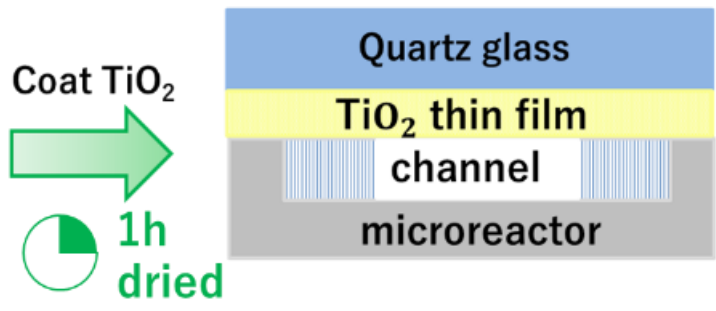

(b)

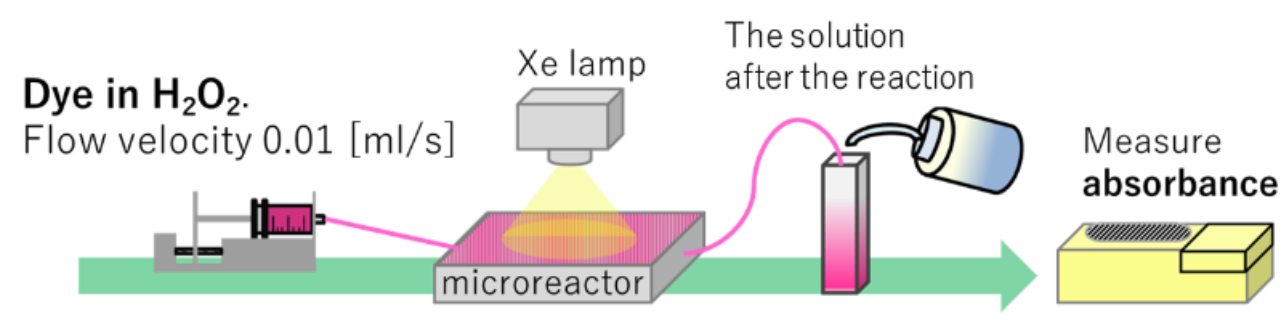

Figure 1 (a) Coating of $\mathrm{TiO}_{2}$ on the glass substrate of the microreactor; (b) Experimental setup of the $\mathrm{TiO}_{2}$ photocatalytic microreactor system. 


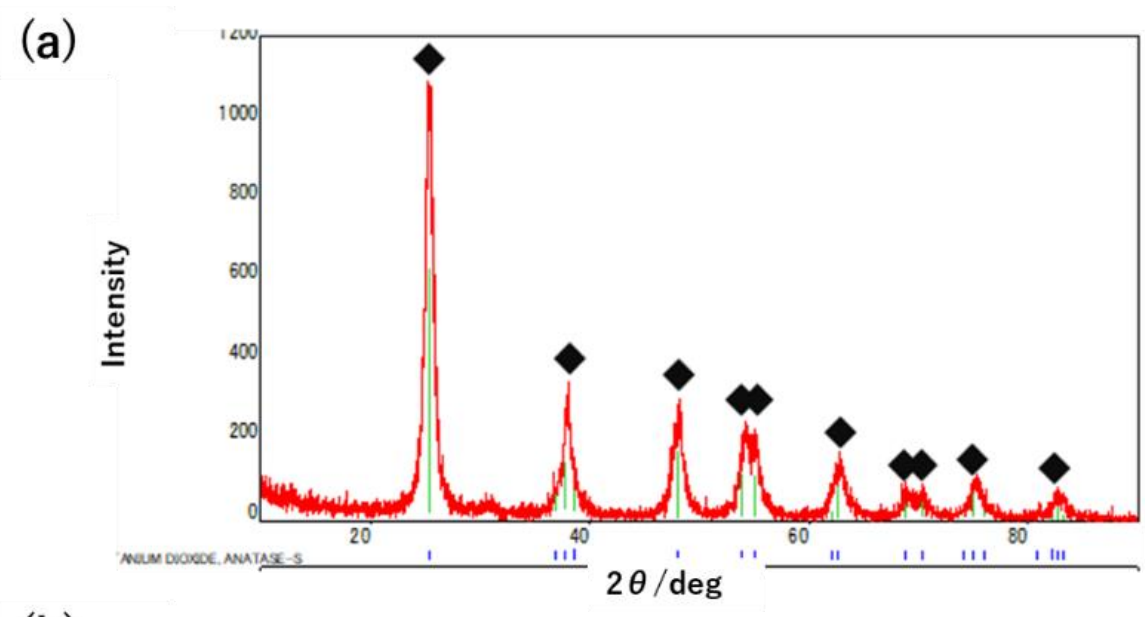

(b)

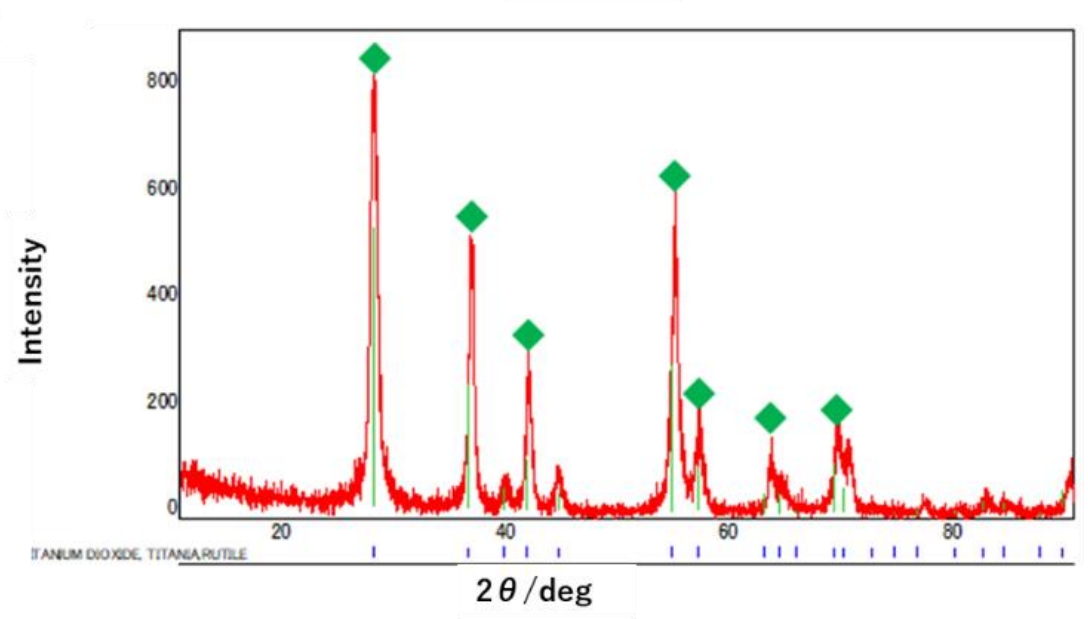

Figure 2 (a) XRD patterns of the $\mathrm{TiO}_{2}$ films on the glass substrate prepared by the calcination of (a) $\mathrm{TiO}_{2}$ sol (AT-01, Photo-Catalytic Materials) and (b) $\mathrm{TiO}_{2}$ sol (RA-06, Taki Co. Ltd.)

\subsection{Experimental Procedures}

The schematic figure of the experimental setup is given in Figure $1(\mathrm{~b})$. The azo dye solution injected by the microsyringe flowed to the microreactor at a speed of about $0.1 \mu \mathrm{L} / \mathrm{min}$. Meanwhile, a 150W Xe lamp (L2273, Hamamatsu Co. Ltd.) was used to irradiate the $\mathrm{TiO}_{2}$ films on the quartz glass attached to the flowing dye solution in the microreactor. Upon ceasing the flow inside the microreactor, the azo dye solution was collected in a glass container and used for the evaluation of the degradation efficiency by measuring the absorbance of the azo dye solution. The absorbance of the azo dye solution was recorded by a spectrometer (Lambda 35, Perkin Elmer, Inc.). The degradation efficiency is defined by the following equation based on the ratio of the absorbance of the azo dye solution with and without the photocatalytic reactions: Degradation efficiency $(\%)=100-\{$ (absorbance before reaction) $/($ absorbance after reaction $) \times 100\}$. In order to understand the effect of $\mathrm{H}_{2} \mathrm{O}_{2}$ addition, a certain concentration of $\mathrm{H}_{2} \mathrm{O}_{2}$ was mixed in the azo dye solution, which was injected into the microreactor using the microsyringe. In the present study, three types of azo dyes (acid orange 7, acid red 151, and acid yellow 23) were used without any further purification. In order to confirm that the films of anatase and rutile $\mathrm{TiO}_{2}$ were prepared by the sols of AT-01 and RA-06, respectively, the UV absorption spectra of these films were recorded. 
The results are shown in Figure 3. The absorption peaks of the anatase and rutile films were observed at $380 \mathrm{~nm}$ and $400 \mathrm{~nm}$, respectively. It is well known that the rutile $\mathrm{TiO}_{2}$ shows an absorption peak at a longer wavelength than anatase. The present results were consistent with the XRD patterns to confirm that the films of the sol AT-01 and sol RA-06 corresponded to the anatase and rutile forms, respectively.

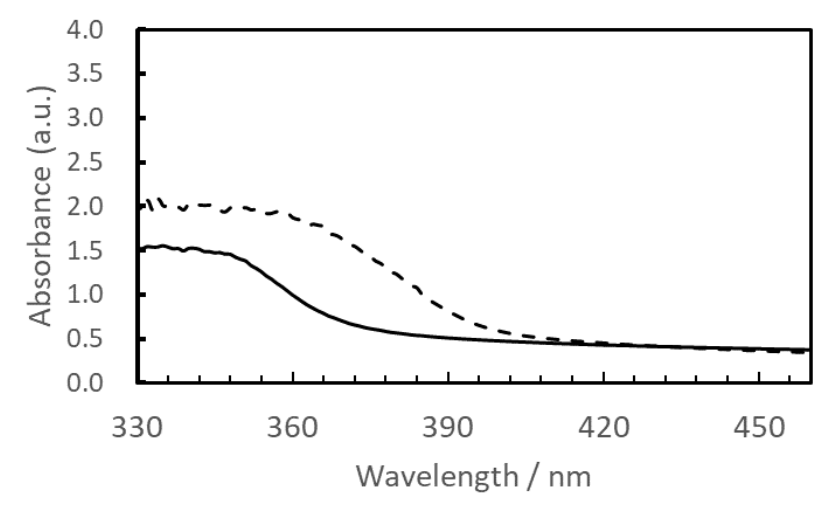

Figure 3 UV absorption spectra of the $\mathrm{TiO}_{2}$ film on the glass substrate prepared by the calcination of (a) $\mathrm{TiO}_{2}$ sol (AT-01, Photo-Catalytic Materials) (solid line) and (b) $\mathrm{TiO}_{2}$ sol (RA-06, Taki Co. Ltd.) (dashed line)

\section{Results}

\subsection{Preliminary Experiment: Measurement of the Fluorescence of Rhodamine 6G in the Microreactor}

Before measuring the photocatalytic degradation efficiencies of the azo dyes in the photocatalytic microreactor by monitoring the change in their absorbance after the completion of the photocatalytic reaction, the in-situ measurement of the degradation process was carried out using the real-time fluorescence probe techniques. For the real-time fluorescence probe techniques, the quartz glass capillary was connected to the end of the flow channel in the microreactor instead of collecting the dye solutions that flowed through them. Further, the fluorescence of Rhodamine $G$ in the glass capillary was recorded. The schematic figure of this experimental setup is shown in Figure 4. In the present experiment, Rhodamine $\mathrm{G}$ was used due to its strong fluorescence upon excitation with a $550 \mathrm{~nm}$ light. The wavelength of irradiated light was chosen by dispersing and selecting the wavelength of a metal halide lamp using a monochromator. The time evolution of the fluorescence intensity of Rhodamine $\mathrm{G}$ is given in Figure 5. The temporal decay of the fluorescence intensity was observed after the initiation of the irradiation of the Xe lamp. The time of the decay was found to be dependent on the flow rate, as shown in Figure 5. Since the Xe lamp irradiated the whole area of the quartz glass attached to the top of the microreactor, the dye solution of Rhodamine $G$ continuously decomposed as far as the UV light irradiated the flowed azo dye solution in the microreactor due to the photocatalytic reaction of the $\mathrm{TiO}_{2}$ film within the system. Since the dye solution at the entrance of the microreactor suffered the $\mathrm{TiO}_{2}$ photocatalytic reactions for a longer time, the fluorescence intensity 
proportional to the concentration of Rhodamine $\mathrm{G}$ continued to decay until the solution reached the end of the microreactor.

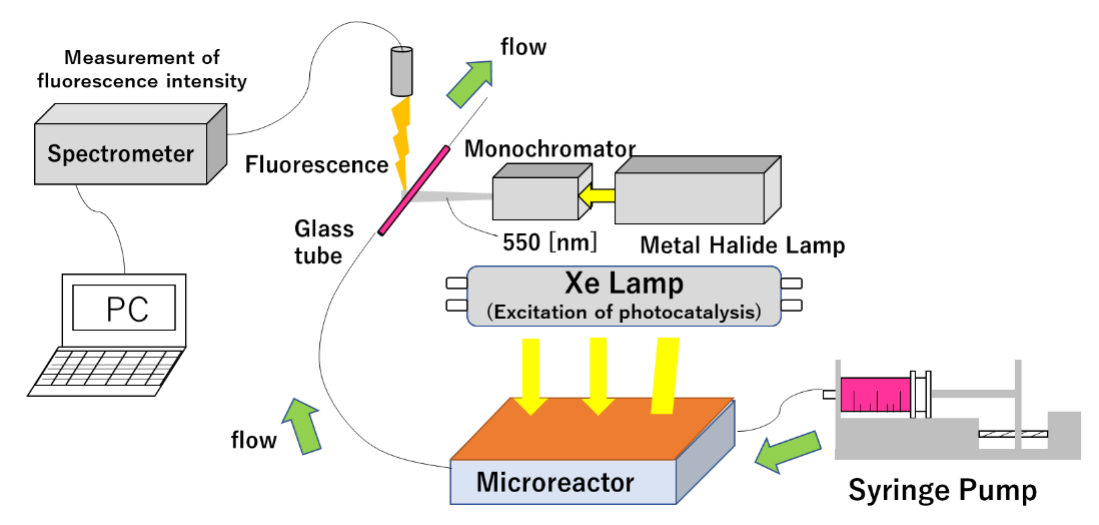

Figure 4 Schematic figure of the experimental setup: In-situ fluorescence probe techniques.
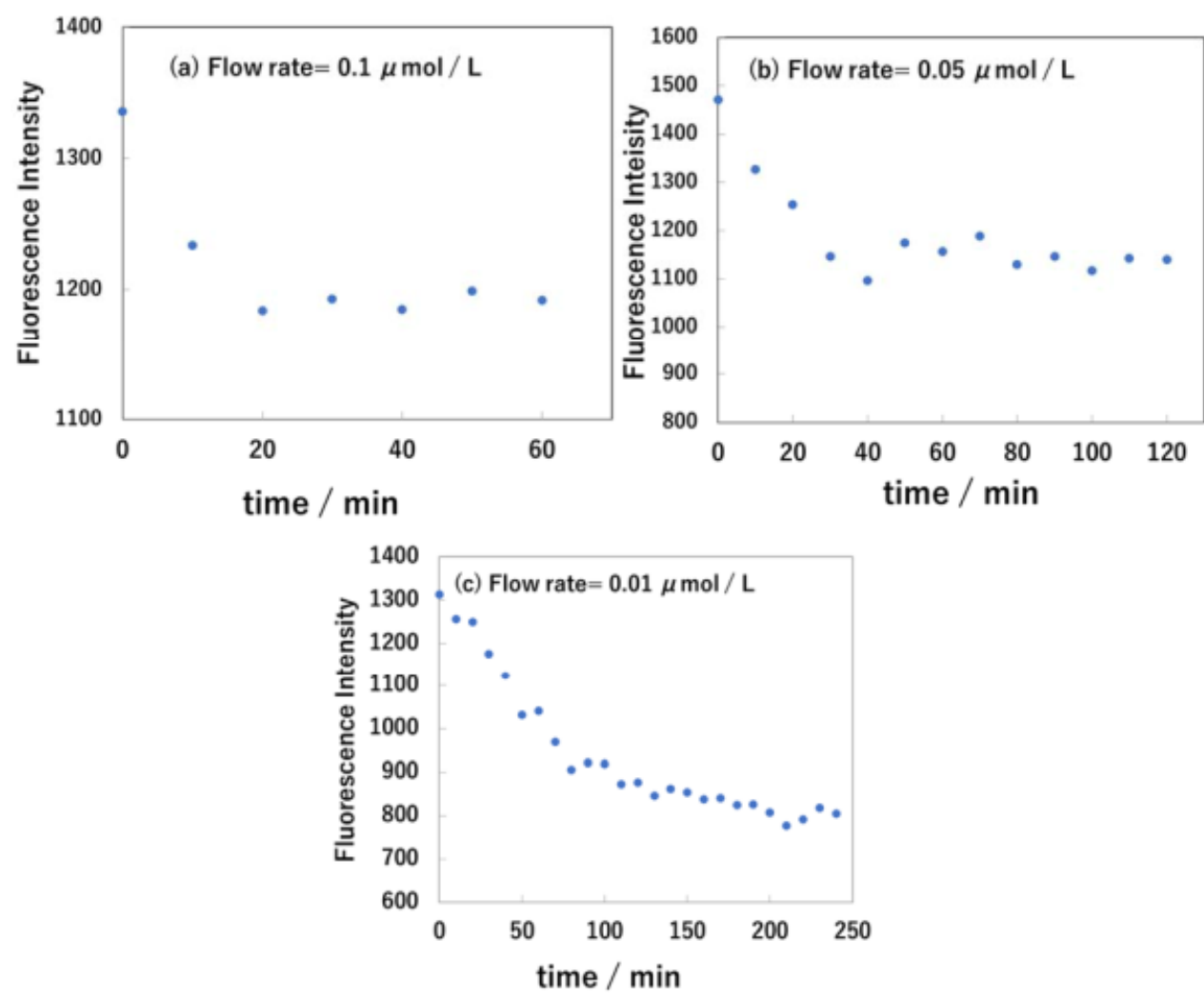

Figure 5 Temporal evolution of the fluorescence intensity of Rhodamine 6G. The flow rates are (a) 0.1 (b) 0.05 and (c) $0.01 \mu \mathrm{mol} / \mathrm{L}$, respectively.

Considering the whole length of the reaction flow in the microreactor as $L(m)$ and the time duration taken to achieve constant fluorescence intensity as $t_{0}(\mathrm{sec})$, the flow rate is expected to be proportional to the value of $L / t_{0}$. Since the length of the flow in the microreactor $L(m)$ is constant, the flow rate is expected to be proportional to the reciprocal to the time taken to achieve constant fluorescence intensity (that is, $t_{0}(\mathrm{sec})$ ). The reciprocal of the time taken to 
achieve constant fluorescence intensity of rhodamine $\mathrm{G}$ versus flow rate was plotted, as shown in Figure 6.

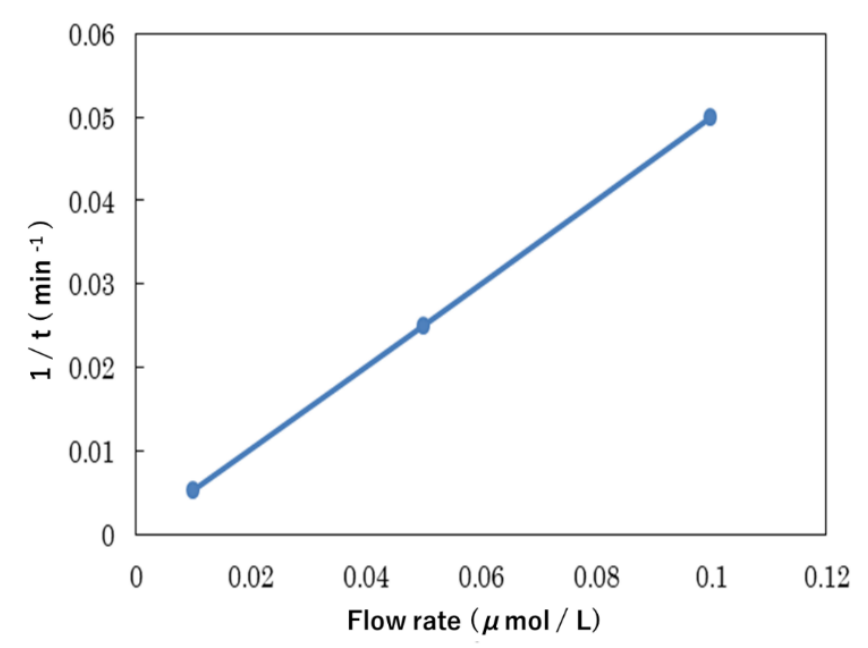

Figure 6 Relationship between the reciprocal of the time taken to achieve constant fluorescence intensity and flow rate of the microreactor.

As shown in Figure 6, a linear plot was obtained between the reciprocal of the time taken to achieve constant fluorescence intensity of rhodamine $\mathrm{G}$ and flow rate, suggesting that the decay of the fluorescence intensity was attributed to the photocatalytic reaction inside the microreactor caused by the irradiation of the microreactor with the Xe lamp. It was also found that the fluorescence intensity was constant in the absence of UV light irradiation on the Rhodamine 6G solution, suggesting no or very little adsorption of the dye on the wall of the microreactor or quartz glass during the flow process.

Thus, the azo dye solution at the end of the flow channel in the microreactor was irradiated with Xe lamp to evaluate the degradation efficiency of the photocatalysis in the following experiments.

\subsection{Effects of the Addition of $\mathrm{H}_{2} \mathrm{O}_{2}$ : Comparison between Anatase and Rutile $\mathrm{TiO}_{2}$}

Since the degradation process in the microreactor by the occurrence of photocatalytic reaction was confirmed in the present system, the effects of $\mathrm{H}_{2} \mathrm{O}_{2}$ on the photocatalytic degradation efficiency were investigated. In order to perform this experiment, a certain amount of $\mathrm{H}_{2} \mathrm{O}_{2}$ was mixed with the azo dye solution and injected into the microreactor. The azo dye with an acid orange 7 was used for the test. The results are presented in Figure 7. In the anatase $\mathrm{TiO}_{2}$ film (AT01, Photo-Catalytic Materials), the degradation efficiency monotonically decreased with the increasing concentration of $\mathrm{H}_{2} \mathrm{O}_{2}$, as shown in Figure 7(a). On the other hand, in the rutile $\mathrm{TiO}_{2}$ film (RA-06, Taki Chemical), the degradation efficiency initially increased with the concentration of $\mathrm{H}_{2} \mathrm{O}_{2}$ and then started to decrease as the concentration of $\mathrm{H}_{2} \mathrm{O}_{2}$ reached $10 \mathrm{mM}$, as shown Figure $7(b)$. There have been previous reports on the acceleration of the $\mathrm{TiO}_{2}$ photocatalytic reaction by the addition of $\mathrm{H}_{2} \mathrm{O}_{2}$, but no previous investigations on the effects of $\mathrm{H}_{2} \mathrm{O}_{2}$ on the degradation efficiency of the $\mathrm{TiO}_{2}$ crystal forms, such as anatase and rutile. Hirakawa et al. [14] reported that the anatase $\mathrm{TiO}_{2}$ form released less amount of $\mathrm{OH}$ radicals upon the addition of $\mathrm{H}_{2} \mathrm{O}_{2}$, while the 
rutile form showed enhanced $\mathrm{OH}$ radical formation. The present results are consistent with the reported experimental observations. Harir et al. [11] performed a detailed kinetic study of the $\mathrm{H}_{2} \mathrm{O}_{2} / \mathrm{TiO}_{2}$ system using commercially available $\mathrm{TiO}_{2}$ (P25, Deggusa) powders. Also, the effect of $\mathrm{H}_{2} \mathrm{O}_{2}$ on photocatalytic activity was investigated and reported to be maximum at around $10 \mathrm{mM}$ of $\mathrm{H}_{2} \mathrm{O}_{2}$.
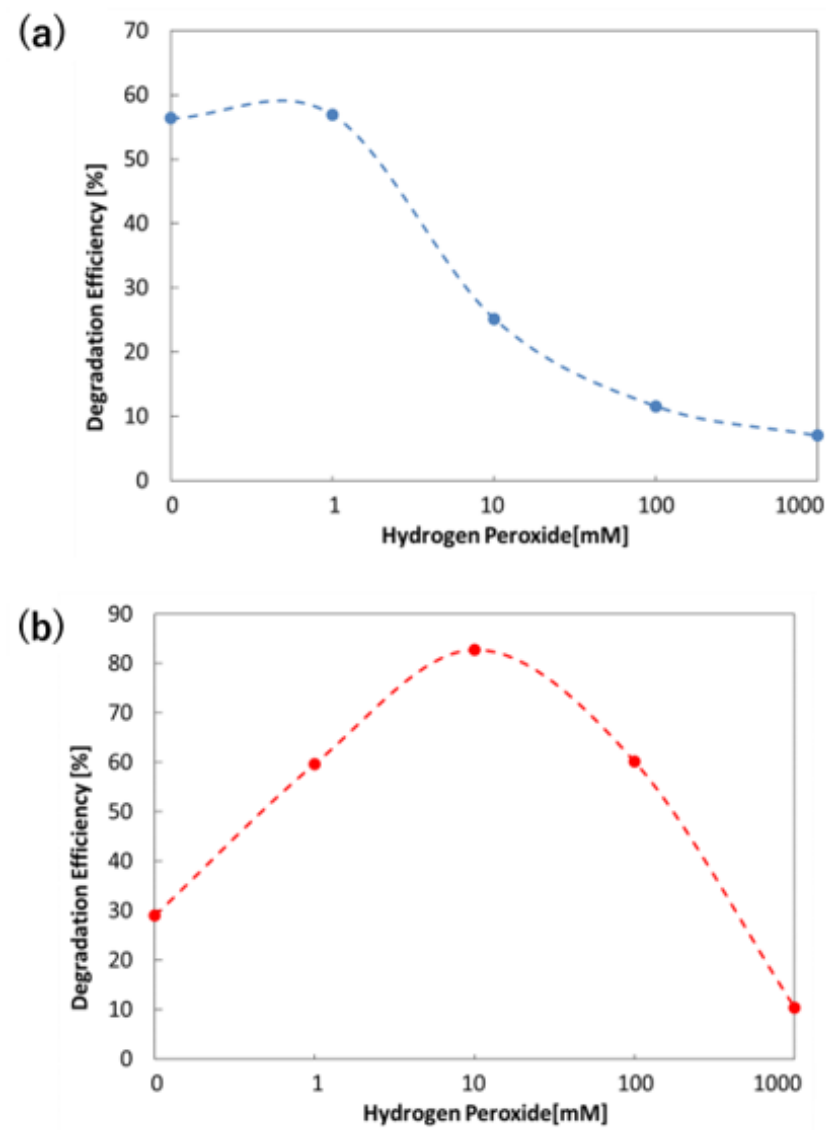

Figure 7 Relationship between the concentration of $\mathrm{H}_{2} \mathrm{O}_{2}$ versus degradation efficiency (\%) of acid orange 7 in the UV-irradiated microreactor coated with the $\mathrm{TiO}_{2}$ film of (a) anatase form and (b) rutile form.

The inhibition effects of $\mathrm{H}_{2} \mathrm{O}_{2}$ on the photocatalytic activity of $\mathrm{TiO}_{2}$ under relatively high $\mathrm{H}_{2} \mathrm{O}_{2}$ concentration were reported. The previous experimental results are consistent with the current observation of the rutile form. Since the photocatalytic $\mathrm{TiO}_{2}$ powders (P25, Degussa) consisted of the mixed phases of anatase and rutile, a mixed-phase $\mathrm{TiO}_{2}$ film was developed on the quartz glass of the microreactor to find the effect of $\mathrm{H}_{2} \mathrm{O}_{2}$ on the photocatalytic activity in the present study. The AT-01 and RA-06 sols were mixed to develop this mixed-phase film. The results are presented in Figure 8. Irreversible to the anatase-rutile ratios of $\mathrm{TiO}_{2}$, degradation efficiency, The photocatalytic activity was maximum at around $10 \mathrm{mM}$ of $\mathrm{H}_{2} \mathrm{O}_{2}$, which was consistent with the results of Harir et al. [11], suggesting that the effect of $\mathrm{H}_{2} \mathrm{O}_{2}$ on the degradation efficiency was attributed to the crystal forms. In other words, the rutile form in the mixed crystal phase of $\mathrm{TiO}_{2}$ played a key role in the effect of $\mathrm{H}_{2} \mathrm{O}_{2}$ addition. The irreversible morphology of the $\mathrm{TiO}_{2}$ was film or powders. 


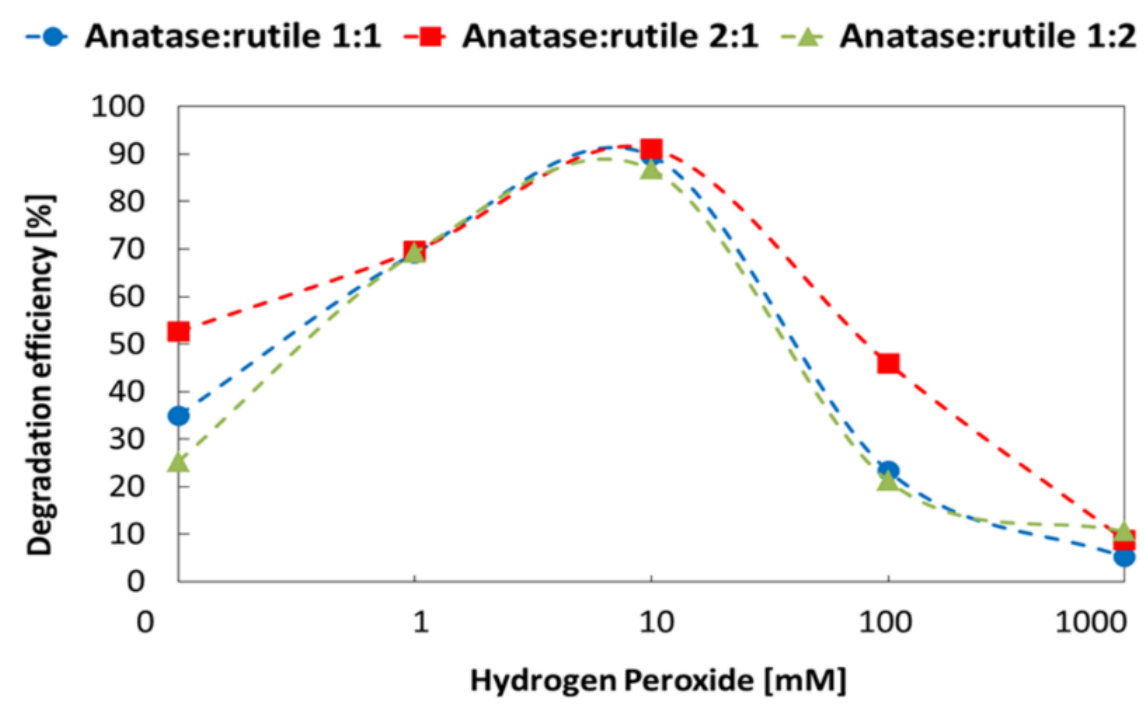

Figure 8 Relationship between the concentration of $\mathrm{H}_{2} \mathrm{O}_{2}$ versus degradation efficiency (\%) of acid orange 7 in the UV-irradiated microreactor coated with the $\mathrm{TiO}_{2}$ film containing different anatase and rutile ratios obtained by mixing anatase $\mathrm{TiO}_{2}$ sols (AT01) and rutile $\mathrm{TiO}_{2}$ sols (RA-06).

To further confirm the effect of $\mathrm{H}_{2} \mathrm{O}_{2}$ concentration on the degradation efficiency of the azo dyes, two different azo dyes of acid red 151 and acid yellow 23 were chosen to perform studies on the anatase and rutile $\mathrm{TiO}_{2}$ films, respectively. The results are illustrated in Figure 9 and Figure 10. Although the acid orange 7 azo dye was replaced by acid red 151 and acid yellow 23, the effect of $\mathrm{H}_{2} \mathrm{O}_{2}$ on the degradation efficiency by anatase and rutile was similar to the trend observed in the former. This suggested that the effect of $\mathrm{H}_{2} \mathrm{O}_{2}$ on the degradation of the azo dyes within the $\mathrm{TiO}_{2} / \mathrm{H}_{2} \mathrm{O}_{2}$ system was different for different crystal structures of $\mathrm{TiO}_{2}$ (anatase or rutile form).

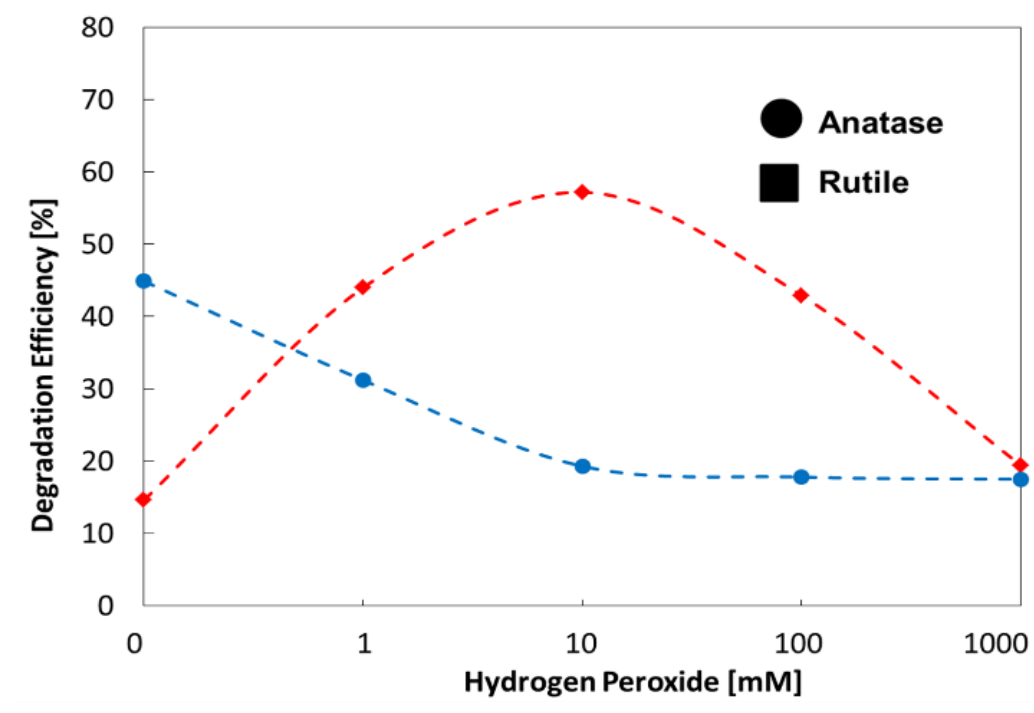

Figure 9 Relationship between the concentration of $\mathrm{H}_{2} \mathrm{O}_{2}$ versus degradation efficiency (\%) of acid red 151 in the UV-irradiated microreactor coated with the $\mathrm{TiO}_{2}$ film of anatase form (filled circle) and rutile form (filled square). 


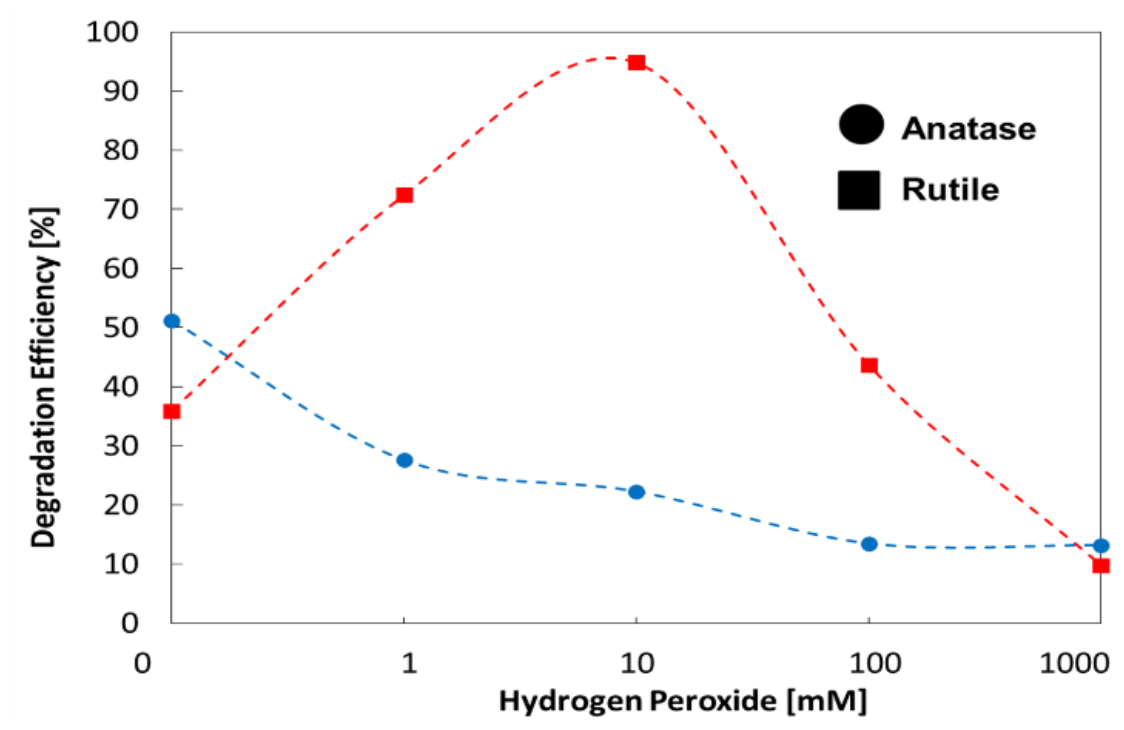

Figure 10 Relationship between the concentration of $\mathrm{H}_{2} \mathrm{O}_{2}$ versus degradation efficiency (\%) of acid yellow 23 in the UV-irradiated microreactor coated with the $\mathrm{TiO}_{2}$ film of anatase form (filled circle) and rutile form (filled square).

\subsection{Effects of the Addition of Scavengers: Discussion of the Mechanism of Anatase and Rutile $\mathrm{TiO}_{2}$ under the Microenvironmental Conditions}

The photocatalytic degradation efficiencies of the three azo dyes by the UV-irradiation of anatase, rutile, and mixed $\mathrm{TiO}_{2}$ in the microreactor were presented. The effects of $\mathrm{H}_{2} \mathrm{O}_{2}$ concentration on the degradation efficiency of $\mathrm{TiO}_{2}$ photocatalysis in the microreactor between anatase and rutile were observed. Although there are still some debates on the relative role of holes and $\mathrm{OH}$ radicals on the degradation of azo dyes, several authors confirmed the significance of $\mathrm{OH}$ radicals on the degradation process $[18,19]$. Since the $\mathrm{OH}$ radicals are formed by two pathways, namely water oxidation and reduction of $\mathrm{H}_{2} \mathrm{O}_{2}$ produced by the multielectron reduction of oxygen, it is important to identify these radicals contributing to the degradation of azo dyes. Therefore, this study attempted to identify the mechanism of the formation of the $\mathrm{OH}$ radicals attributing to the degradation process, which was investigated by the addition of scavengers.

Based on the previous studies, benzoquinone (hereafter, $\mathrm{BQ}$ ) [20] and $\mathrm{KI}$ [21] were used as the electron and hole ( $\mathrm{OH}$ radical) scavengers, respectively, and acid orange 7 was chosen as the representative azo dye solution in the present work. The results are presented in Figure 11 and Figure 12. It was observed that the electron scavengers of $B Q$ showed relatively larger effects compared to the slight effects of $\mathrm{KI}$ on the photocatalytic degradation efficiency of acid orange 7. Since the $\mathrm{OH}$ radicals were formed by the reduction reaction of $\mathrm{O}_{2}$ via $\mathrm{H}_{2} \mathrm{O}_{2}$, the influence of the addition of $\mathrm{BQ}$ on the degradation efficiency of the azo dye (acid orange 7) in the presence of $\mathrm{H}_{2} \mathrm{O}_{2}$ was also investigated. 

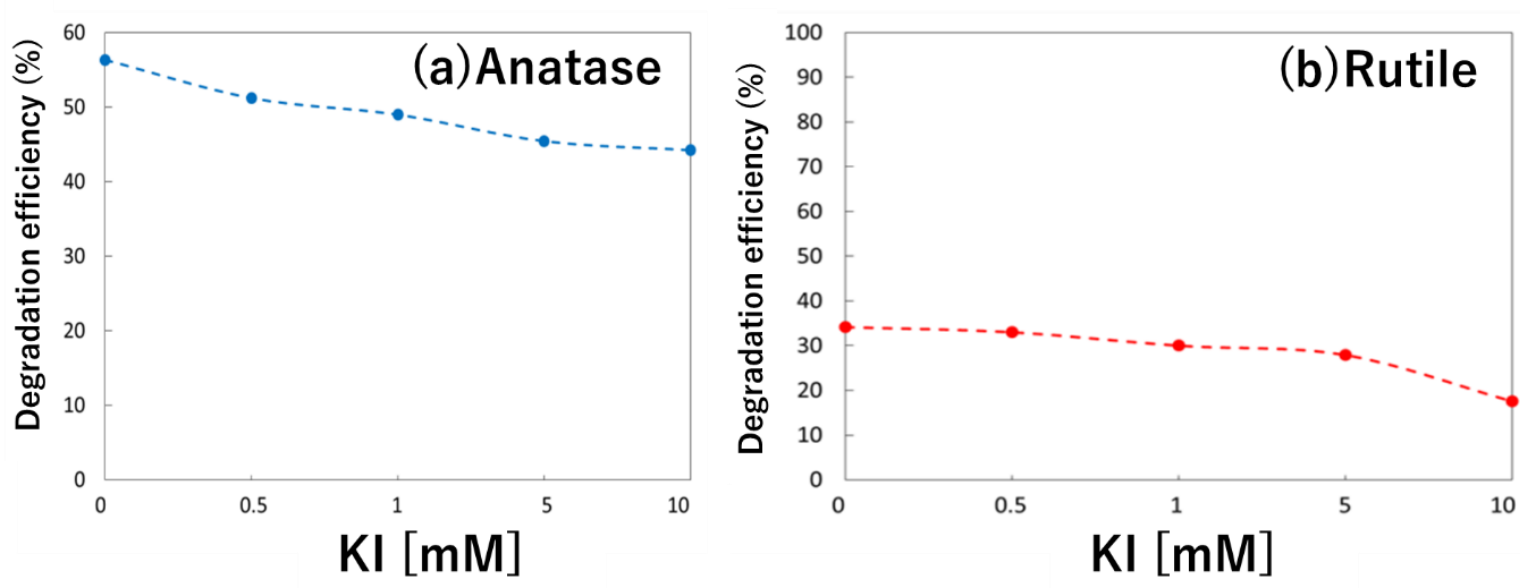

Figure 11 Relationship between the degradation efficiency (\%) of acid orange 7 in the UV-irradiated microreactor coated with the $\mathrm{TiO}_{2}$ film and the concentration of $\mathrm{KI}$ acting as hole scavengers: (a) anatase form of $\mathrm{TiO}_{2}(\mathrm{AT}-01)$ and (b) rutile form of $\mathrm{TiO}_{2}$ (RA-06).

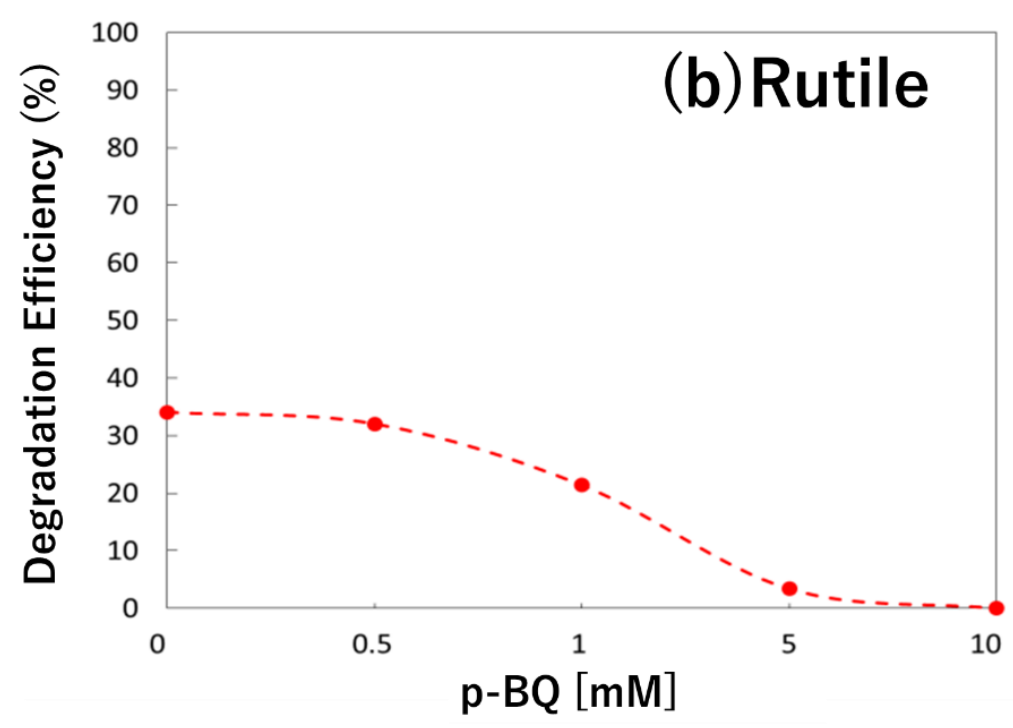

Figure 12 Relationship between the degradation efficiency (\%) of acid orange 7 in the UV-irradiated microreactor coated with the $\mathrm{TiO}_{2}$ film and the concentration of $\mathrm{p}-\mathrm{BQ}$ ( $\mathrm{p}$ benzoquinone) acting as electron scavengers: (a) anatase form of $\mathrm{TiO}_{2}$ (AT-01) and (b) rutile form of $\mathrm{TiO}_{2}$ (RA-06).

The experimental results are presented in Figure 13. It was observed that the influence of $B Q$ on the reduction of the photocatalytic degradation efficiency was very large in the presence of 10 $\mathrm{mM}$ of $\mathrm{H}_{2} \mathrm{O}_{2}$. When the concentration of $\mathrm{BQ}$ rose to $10 \mathrm{mM}$, the degradation efficiency was reduced to zero. The significance of the $\mathrm{OH}$ radicals formed by the reduction reaction by $\mathrm{H}_{2} \mathrm{O}_{2}$ generated by the reduction of $\mathrm{O}_{2}$ on the degradation mechanism was not explained in the literature. Thus, the results of the current study suggested the important role of the $\mathrm{OH}$ radicals formed by the reduction reaction. Finally, the mechanism of the scavengers and $\mathrm{OH}$-radical formation by the photocatalytic reaction is illustrated in Figure 14. Thus, the difference in the 
photocatalytic degradation efficiency of $\mathrm{TiO}_{2}$ was attributed to the different reactivity of the anatase and rutile forms in the reduction reaction. Nosaka and co-workers $[14,22]$ reported that the different structures of the peroxy species of the $\mathrm{TiO}_{2}$ surfaces in the anatase and rutile forms contributed to the difference in reactivity, as illustrated in Figure 15. The present results on the different photocatalytic degradation efficiencies upon the $\mathrm{H}_{2} \mathrm{O}_{2}$ addition might be attributed to the same factor, as reported by Nosaka et al. [22, 23], Hayashi et al. [24] and Murakami et al. [25, 26 ] in the literature. Further studies are required to clarify their significance in the degradation mechanism.
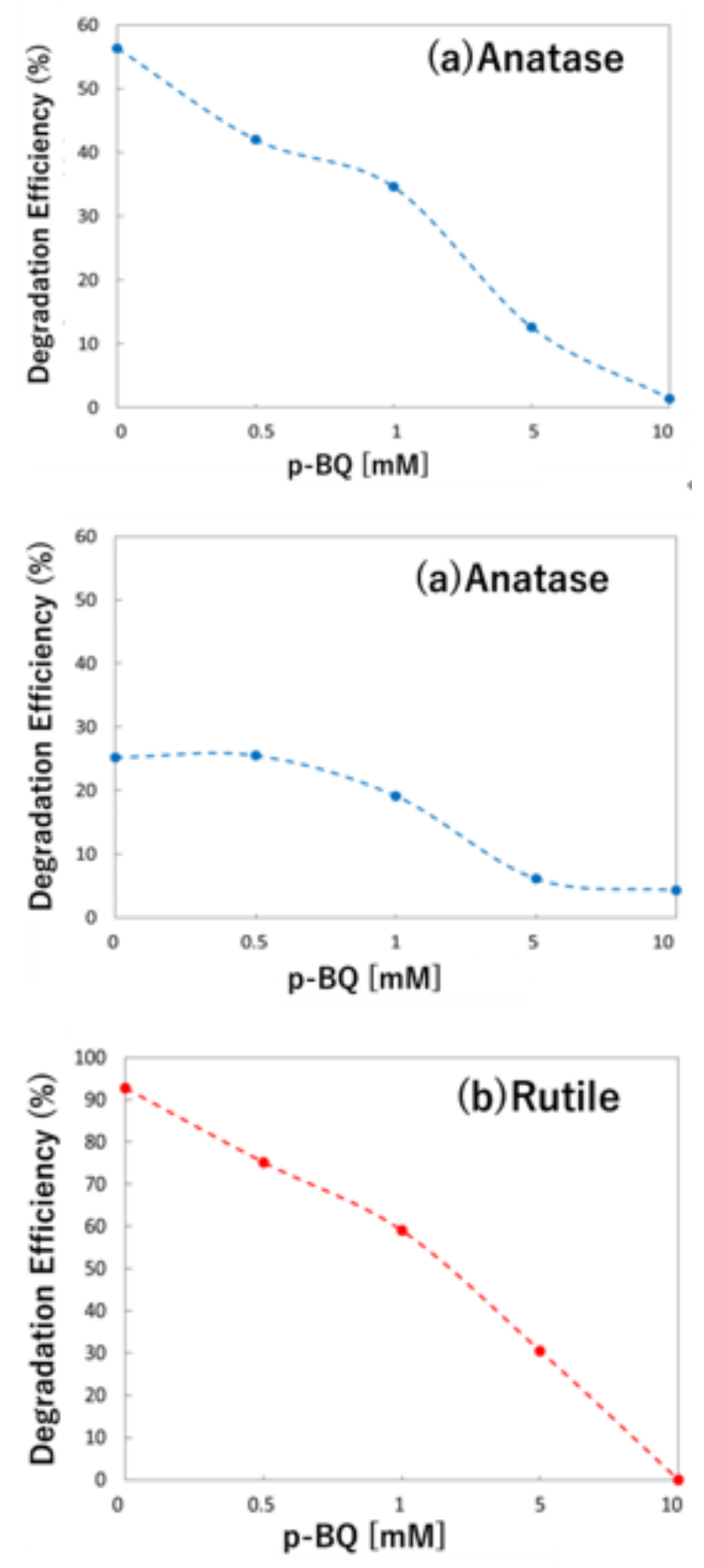

Figure 13 Relationship between the degradation efficiency (\%) of acid orange 7 in the UV-irradiated microreactor coated with the $\mathrm{TiO}_{2}$ film and the concentration of $\mathrm{p}-\mathrm{BQ}$ ( $\mathrm{p}$ benzoquinone) acting as electron scavengers in the presence of $10 \mathrm{mM}$ of $\mathrm{H}_{2} \mathrm{O}_{2}$ : (a) anatase form of $\mathrm{TiO}_{2}$ (AT-01) and (b) rutile form of $\mathrm{TiO}_{2}$ (RA-06). 


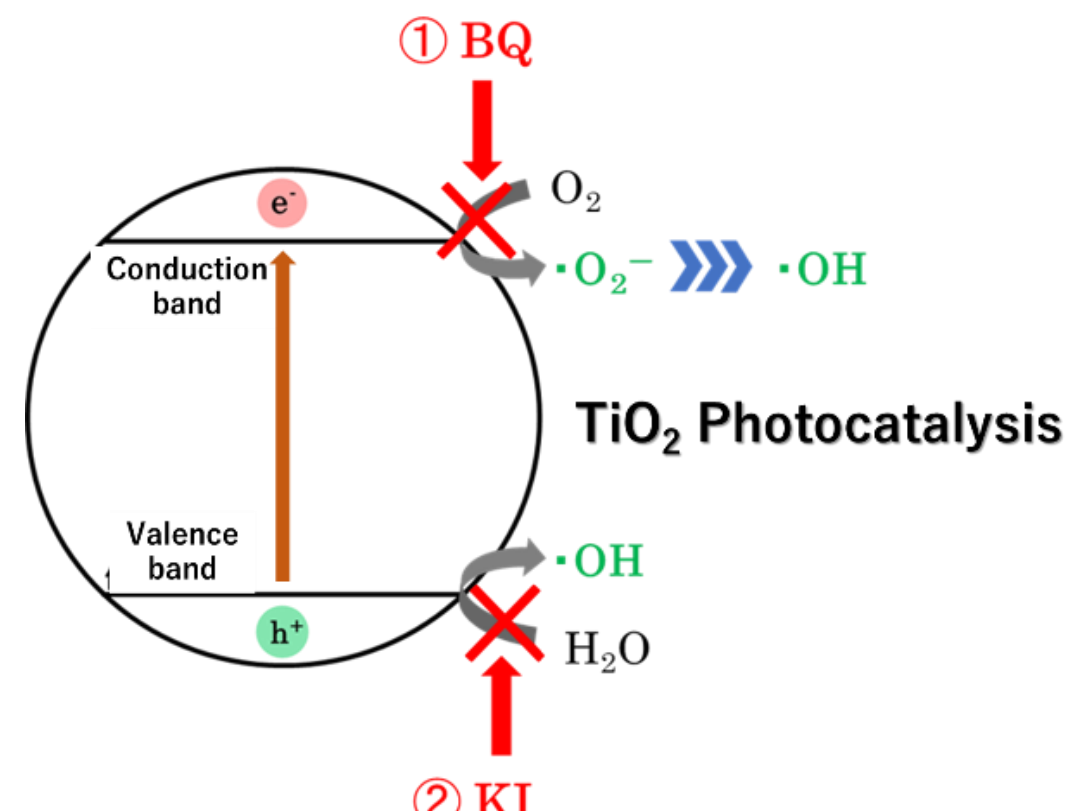

Figure 14 Schematic representation of the inhibition effects of each scavenger ( $\mathrm{KI}$ and $\mathrm{p}-\mathrm{BQ}$ ) on the $\mathrm{TiO}_{2}$ photocatalytic reaction.

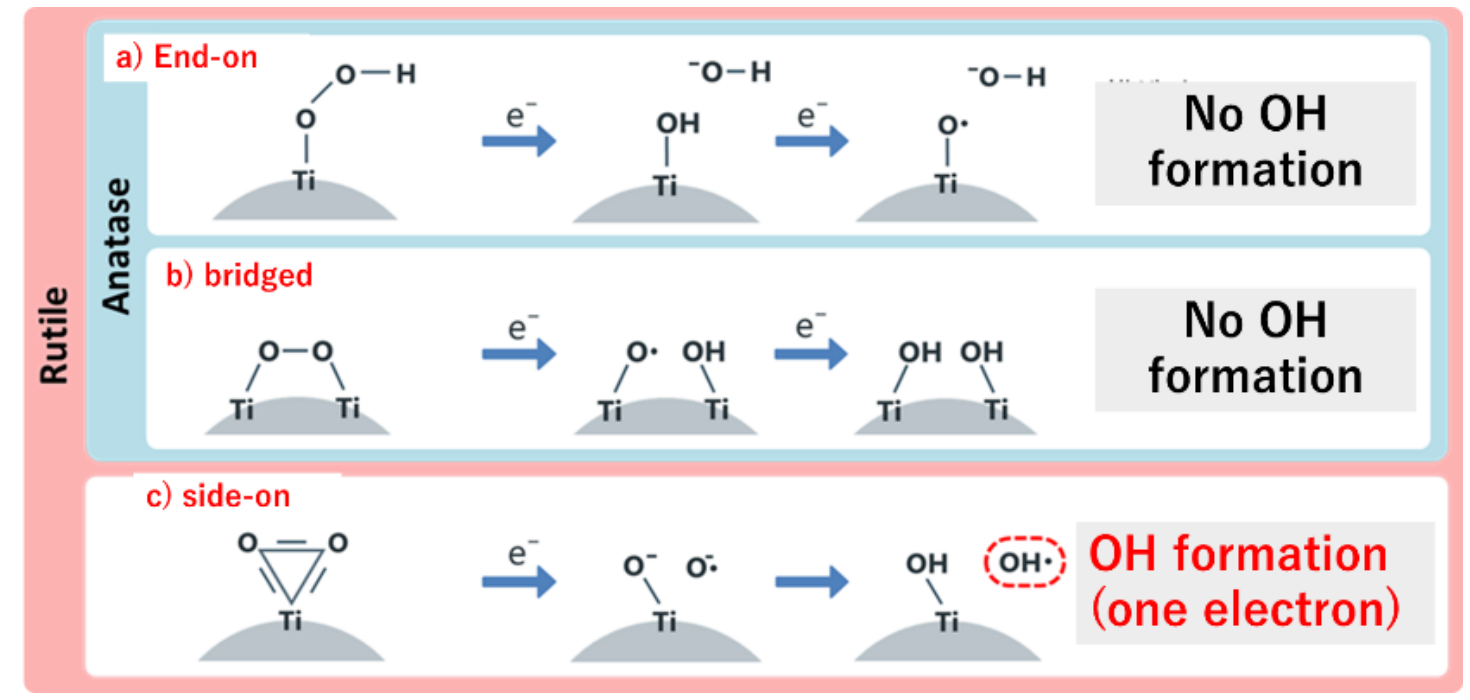

Figure 15 Schematic representation of the peroxy species on the anatase and rutile $\mathrm{TiO}_{2}$ surfaces, and the proposed mechanism for the formation of $\mathrm{OH}$ from the peroxy species on the $\mathrm{TiO}_{2}$ surface [14].

\section{Conclusions}

The degradation efficiency of three azo dyes in the photocatalytic microreactor system was studied along with the effect of $\mathrm{H}_{2} \mathrm{O}_{2}$ on the degradation process. It was found that the photocatalytic degradation efficiency of acid orange 7 within the $\mathrm{TiO}_{2}$ photocatalytic microreactor system was monotonically decreased in the presence of the anatase form of $\mathrm{TiO}_{2}$. However, the degradation efficiency was enhanced in the presence of the rutile form of $\mathrm{TiO}_{2}$ up to the $\mathrm{H}_{2} \mathrm{O}_{2}$ concentration of $10 \mathrm{mM}$ and then decreased with the increase in the concentration of $\mathrm{H}_{2} \mathrm{O}_{2}$. The 
other azo dyes, such as acid red 151 and acid yellow 23, also showed similar trends. In order to investigate the effect of $\mathrm{H}_{2} \mathrm{O}_{2}$ on the photocatalytic degradation efficiency of the anatase and rutile forms, scavengers of holes and electrons were added in the photocatalytic microreactor systems. From these experiments, the importance of the $\mathrm{OH}$ radicals formed by the reduction of $\mathrm{O}_{2}$ was suggested. Thus, it was speculated that the difference in the effect of $\mathrm{H}_{2} \mathrm{O}_{2}$ on the photocatalytic degradation efficiency was probably attributed to the different reactivity and reduction reactions of $\mathrm{H}_{2} \mathrm{O}_{2}$ on the anatase and rutile $\mathrm{TiO}_{2}$ surfaces.

\section{Acknowledgments}

The authors acknowledge Prof. Kenji Katayama for helpful advice for the fabrication of the microreactor system. One of the authors also acknowledges the support from the GEAR 5.0 Project of the National Institute of Technology (KOSEN) in Japan.

\section{Author Contributions}

Mr. Minato Nakamura performed experiments and analyses. Prof. Yoshinori Murakami supervised the research.

\section{Funding}

No organization or foundation was funded for this research.

\section{Competing Interests}

The authors have declared that no competing interests exist.

\section{References}

1. Melchionna M, Fornasiero P. Updates on the roadmap for photocatalysis. ACS Catal. 2020; 10 : 5493-5501.

2. Khan S, Khan A, Ali N, Ahmad S, Ahmad W, Malik S, et al. Degradation of Congo red dye using ternary metal selenide-chitosan microspheres as robust and reusable catalysts. Environ Technol Innov. 2021; 22: 101402.

3. Hoffmann MR, Martin ST, Choi W, Bahnemann DW. Environmental applications of semiconductor photocatalysis. Chem Rev. 1995; 95: 69-96.

4. Koe WS, Lee JW, Chong WC, Pang YL, Sim LC. An overview of photocatalytic degradation: Photocatalysts, mechanisms, and development of photocatalytic membrane. Environ Sci Pollut Res. 2020; 27: 2522-2565.

5. Ali N, Ali F, Khurshid R, Ali Z, Afzal A, Bilal M, et al. $\mathrm{TiO}_{2}$ nanoparticles and epoxy- $\mathrm{TiO}_{2}$ nanocomposites: A review of synthesis, modification strategies, and photocatalytic potentialities. J Inorg Organomet Polym Mater. 2020; 30: 4829-4846.

6. Hashimoto $\mathrm{K}$, Irie $\mathrm{H}$, Fujishima $\mathrm{A}$. $\mathrm{TiO}_{2}$ photocatalysis: A historical overview and future prospects. Jpn J Appl Phys. 2005; 44: 8269-8285. 
7. Dambournet D, Belharouak I, Amine K. Tailored preparation methods of $\mathrm{TiO}_{2}$ anatase, rutile, brookite: Mechanism of formation and electrochemical properties. Chem Mater. 2010; 22: 1173-1179.

8. Vequizo JJ, Matsunaga H, Ishiku T, Kamimura S, Ohno T, Yamakata A. Trapping-induced enhancement of photocatalytic activity on brookite $\mathrm{TiO}_{2}$ powders: Comparison with anatase and rutile $\mathrm{TiO}_{2}$ powders. ACS Catal. 2017; 7: 2644-2651.

9. Sun $\mathrm{Q}, \mathrm{Xu}$ Y. Evaluating intrinsic photocatalytic activities of anatase and rutile $\mathrm{TiO}_{2}$ for organic degradation in water. J Phys Chem C. 2010; 114: 18911-18918.

10. Zhang J, Zhou P, Liu J, Yu J. New understanding of the difference of photocatalytic activity among anatase, rutile and brookite $\mathrm{TiO}_{2}$. Phys Chem Chem Phys. 2014; 16: 20382-20386.

11. Harir M, Gaspar A, Kanawati B, Fekete A, Frommberger M, Martens D, et al. Photocatalytic reactions of imazamox at $\mathrm{TiO}_{2}, \mathrm{H}_{2} \mathrm{O}_{2}$ and $\mathrm{TiO}_{2} / \mathrm{H}_{2} \mathrm{O}_{2}$ in water interfaces: Kinetic and photoproducts study. Appl Catal B Environ. 2008; 84: 524-532.

12. Fernández J, Kiwi J, Baeza J, Freer J, Lizama C, Mansilla HD. Orange II photocatalysis on immobilised $\mathrm{TiO}_{2}$ : Effect of the $\mathrm{pH}$ and $\mathrm{H}_{2} \mathrm{O}_{2}$. Appl Catal B Environ. 2004; 48: 205-211.

13. Li X, Chen $\mathrm{C}$, Zhao J. Mechanism of photodecomposition of $\mathrm{H}_{2} \mathrm{O}_{2}$ on $\mathrm{TiO}_{2}$ surfaces under visible light irradiation. Langmuir. 2001; 17: 4118-4122.

14. Hirakawa $\mathrm{T}$, Yawata $\mathrm{K}$, Nosaka $\mathrm{Y}$. Photocatalytic reactivity for $\mathrm{O}_{2} \bullet^{-}$and $\mathrm{OH} \bullet$ radical formation in anatase and rutile $\mathrm{TiO}_{2}$ suspension as the effect of $\mathrm{H}_{2} \mathrm{O}_{2}$ addition. Appl Catal A Gen. 2007; 325: 105-111.

15. Hirakawa T, Nosaka Y. Properties of $\mathrm{O}^{\circ}$ - and $\mathrm{OH}^{\bullet}$ formed in $\mathrm{TiO}_{2}$ aqueous suspensions by photocatalytic reaction and the influence of $\mathrm{H}_{2} \mathrm{O}_{2}$ and some ions. Langmuir. 2002; 18: 32473254.

16. Mason BP, Price KE, Steinbacher JL, Bogdan AR, McQuade DT. Greener approaches to organic synthesis using microreactor technology. Chem Rev. 2007; 107: 2300-2318.

17. Wang N, Zhang X, Wang Y, Yu W, Chan HL. Microfluidic reactors for photocatalytic water purification. Lab Chip. 2014; 14: 1074-1082.

18. da Silva CG, Faria JL. Photochemical and photocatalytic degradation of an azo dye in aqueous solution by UV irradiation. J Photochem Photobiol A. 2003; 155: 133-143.

19. $\mathrm{Wu} \mathrm{CH}$. Comparison of azo dye degradation efficiency using UV/single semiconductor and UV/coupled semiconductor systems. Chemosphere. 2004; 57: 601-608.

20. Henderson MA, Shen M. Electron-scavenging chemistry of benzoquinone on $\mathrm{TiO}_{2}$ (110). Top Catal. 2017; 60: 440-445.

21. Wang $\mathrm{Y}$, Zhang P. Photocatalytic decomposition of perfluorooctanoic acid (PFOA) by $\mathrm{TiO}_{2}$ in the presence of oxalic acid. J Hazard Mater. 2011; 192: 1869-1875.

22. Nosaka Y, Nosaka A. Understanding hydroxyl radical $\left({ }^{\circ} \mathrm{OH}\right)$ generation processes in photocatalysis. ACS Energy Lett. 2016; 1: 356-359.

23. Nosaka Y, Nosaka AY. Generation and detection of reactive oxygen species in photocatalysis. Chem Revi. 2017; 117: 11302-11336.

24. Hayashi T, Nakamura K, Suzuki T, Saito N, Murakami Y. OH radical formation by the photocatalytic reduction reactions of $\mathrm{H}_{2} \mathrm{O}_{2}$ on the surface of plasmonic excited $\mathrm{Au}-\mathrm{TiO}_{2}$ photocatalysts. Chem Phys Lett. 2020; 739: 136958. 
25. Murakami Y, Kenji E, Nosaka AY, Nosaka Y. Direct detection of $\mathrm{OH}$ radicals diffused to the gas phase from the UV-irradiated photocatalytic $\mathrm{TiO}_{2}$ surfaces by means of laser-induced fluorescence spectroscopy. J Phys Chem B. 2006; 110: 16808-16811.

26. Murakami Y, Endo K, Ohta I, Nosaka AY, Nosaka Y. Can $\mathrm{OH}$ radicals diffuse from the UVirradiated photocatalytic $\mathrm{TiO}_{2}$ surfaces? Laser-induced-fluorescence study. J Phys Chem C. 2007; 111: 11339-11346.

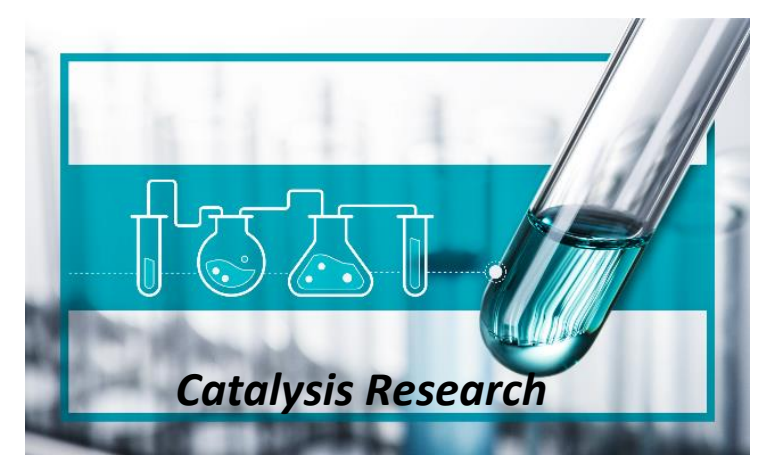

Enjoy Catalysis Research by:

1. Submitting a manuscript

2. Joining in volunteer reviewer bank

3. Joining Editorial Board

4. Guest editing a special issue

For more details, please visit:

http://www.lidsen.com/journals/cr 